\title{
Vengefully Ever After: Destiny Beliefs, State Attachment Anxiety, and Forgiveness
}

\author{
Eli J. Finkel \\ Northwestern University
}

\author{
Jeni L. Burnette \\ University of Richmond
}

\begin{abstract}
Lauren E. Scissors
Northwestern University

Two studies examined how destiny beliefs (that potential relationships are or are not "meant to be") interact with state attachment anxiety to predict forgiveness tendencies. In Study 1, participants experienced an experimental manipulation of attachment anxiety (vs. security) before indicating the degree to which they would forgive a series of hypothetical partner offenses. In Study 2, participants reported every 2 weeks for 6 months (14 waves in total) on offenses enacted by their partner and indicated the degree to which they forgave the partner, both concurrently and 2 weeks later. Consistent with predictions, results revealed Destiny Beliefs $\times$ State Attachment Anxiety interaction effects: Strong (relative to weak) destiny beliefs predicted reduced forgiveness tendencies for individuals experiencing state attachment anxiety, but such beliefs were not associated with forgiveness for individuals experiencing state attachment security. Results from Study 2 suggest that this interaction effect was significantly mediated through trust in the partner.
\end{abstract}

Keywords: forgiveness, implicit theories of relationships, destiny, attachment anxiety, trust

Imagine that you are a college student facing one of the following situations in your romantic relationship: (a) Your partner goes on a date with somebody else; (b) your long-distance partner is, for the 3rd night this week, too busy to talk with you; or (c) your partner cancels plans with you in order to get drunk with friends. How likely would you be to forgive offenses such as these?

The answer to this question is consequential because partner offenses are a nearly inevitable aspect of involvement in long-term romantic relationships (Holmes \& Murray, 1996) and because the manner in which individuals respond to them predicts relational and personal well-being. Although victims' gut-level impulses in response to offenses tend toward grudge and retaliation (Finkel,

Eli J. Finkel and Lauren E. Scissors, Department of Psychology, Northwestern University; Jeni L. Burnette, Department of Psychology, University of Richmond.

Lauren E. Scissors conducted Study 1 (under the direction of Eli J. Finkel) in partial fulfillment of her undergraduate honors thesis requirements at Northwestern University. We gratefully acknowledge Candida Abrahamson, Chris Fraley, Steve Graham, Dan Molden, Madoka Kumashiro, and Sarah Scarbeck for their helpful suggestions on drafts of this article. We also thank Jacob Matthews and Mike Machenry for developing the software for conducting the online surveys, Joel Pollack and Dave Sylva for assistance with data collection, and Chip Knee for engaging with us in stimulating theoretical discussion. Most of all, we thank Paul Eastwick for his important suggestions throughout the preparation of this article.

Correspondence concerning this article should be addressed to Eli J. Finkel, Department of Psychology, Northwestern University, 2029 Sheridan Road, Swift Hall Room 102, Evanston, IL 60208-2710. E-mail: finkel@northwestern.edu
Rusbult, Kumashiro, \& Hannon, 2002; Rusbult, Davis, Finkel, Hannon, \& Olsen, 2006), acting on these retaliatory impulses is the leading predictor of relationship distress (Gottman, 1998). Enacting forgiving responses to offenses, in contrast, predicts the restoration of interpersonal harmony (Fincham, Beach, \& Davila, 2004; Gordon \& Baucom, 2003; Rusbult, Hannon, Stocker, \& Finkel, 2005). Not only does forgiveness predict relational repair following offenses, it has also been linked to healthier physiological functioning (Lawler et al., 2003; Witvliet, Ludwig, \& Vander Laan, 2001), reduced negative affect (Worthington \& Scherer, 2004), and fewer negative physical health symptoms (Toussaint, Williams, Musick, \& Everson, 2001).

Given the relational and personal benefits associated with forgiveness, why do people frequently fail to forgive? One answer is that forgiveness is not easy: It typically requires overriding retaliatory impulses. We investigate the idea that individuals are especially unlikely to forgive when they generally believe that romantic partners either are or are not "meant to be" (destiny beliefs) and are currently experiencing feelings of relational uncertainty and the need for reassurance (state attachment anxiety). We suggest that experiencing heightened state attachment anxiety (vs. security) when responding to offenses renders individuals vulnerable to insecurity and distrustful sentiments, vulnerabilities that are likely to be exacerbated by destiny theorists' tendency to diagnose the long-term potential of the relationship on the basis of the meaning they ascribe to discrete events. Two studies tested the hypothesis that strong (vs. weak) destiny beliefs predict reduced forgiveness for individuals experiencing state attachment anxiety, but that such beliefs exhibit no association with forgiveness for individuals experiencing state attachment security. 
In the next section, we review the literature on implicit theories of relationships, proposing that strong (vs. weak) destiny theorists tend to diagnose the future prospects for their relationship on the basis of the meaning they ascribe to specific relationship events. We then review the literature on attachment dynamics, (a) arguing that experiencing state attachment anxiety (vs. security) when responding to partner offenses directs destiny theorists' diagnostic tendencies toward issues of trust versus distrust and (b) emphasizing the value of conceptualizing attachment representations as state-level variables. Finally, we explore the potential role of trust in mediating the associations between destiny beliefs, state attachment anxiety, and lack of forgiveness.

\section{Implicit Theories of Relationships}

Individuals hold implicit theories of diverse human characteristics (e.g., intelligence, personality), and these theories vary in the degree to which such characteristics are conceptualized as stable versus changeable (for reviews, see Dweck, 2006; Molden \& Dweck, 2006). A new and rapidly expanding literature demonstrates the importance of individuals' implicit theories of romantic relationships (Franiuk, Cohen, \& Pomerantz, 2002; Knee, 1998; Ruvolo \& Rotondo, 1998). Individuals vary in the degree to which they subscribe to destiny beliefs (the belief that romantic relationships are or are not meant to be) and growth beliefs (the belief that relationships can benefit from the effortful resolution of challenges and obstacles; Knee, 1998; Knee, Patrick, \& Lonsbary, 2003). (Franiuk et al., 2002, refer to similar implicit theories, respectively, as "soulmate" beliefs and "work-itout" beliefs.) Destiny beliefs and growth beliefs represent conceptually and statistically independent dimensions rather than two ends of a single dimension (Knee, 1998; Knee, Nanayakkara, Vietor, Neighbors, \& Patrick, 2001; Knee et al., 2003; Knee, Patrick, Vietor, \& Neighbors, 2004).

Although a cursory analysis might lead one to hypothesize that implicit theories would predict relationship outcomes through main effects, evidence for such effects is less consistent than is evidence for interaction effects of destiny or growth beliefs with other relationship factors (for a review, see Knee \& Canevello, 2006). For example, particularly robust effects suggest that individuals' evaluations of their relationship (e.g., closeness) and of their partner (e.g., partner similarity to one's ideal partner) tend to interact with destiny beliefs to predict relationship outcomes: Destiny theorists who positively evaluate the relationship or the partner exhibit especially positive outcomes (e.g., greater relationship persistence and satisfaction), whereas destiny theorists who negatively evaluate the relationship or the partner exhibit especially negative outcomes (Franiuk et al., 2002; Franiuk, Pomerantz, \& Cohen, 2004; Knee, 1998; Knee et al., 2001, 2004; Ruvolo \& Rotondo, 1998). ${ }^{1}$

In the present research, we predicted that although neither destiny beliefs nor growth beliefs would exhibit main effects in predicting forgiveness, these implicit theories would behave quite differently when paired with state attachment anxiety: Strongly subscribing to growth beliefs would not interact with state attachment anxiety to predict forgiveness, whereas strongly subscribing to destiny beliefs would. Strong (vs. weak) destiny theorists, because they believe in the long-term stability of their current relationship impressions, tend to evaluate and diagnose "the compatibility of a potential romantic partner and the future success of the relationship from whatever information is immediately available [italics added]" (Knee \& Canevello, 2006, p. 161; see also Knee et al., 2003). We predicted that these individuals would be likely to analyze their current cognitive and affective experiences when evaluating the meaning of offenses and to draw different long-term conclusions regarding their partner's reliability depending on whether they were experiencing state attachment anxiety (vs. security). Given that (as discussed in greater detail below) strong attachment anxiety, at least at the trait level, has been demonstrated to predict acute concerns about rejection and the tendency to catastrophize the anticipated future consequences of relationship difficulties (Campbell, Simpson, Boldry, \& Kashy, 2005), destiny theorists currently experiencing elevated attachment anxiety are especially likely to conclude that their future with a given romantic partner will be suffused with such unpleasant insecurities. Such long-term conclusions could well cause them to experience distrust in the wake of partner offenses, ultimately causing them to exhibit low levels of forgiveness. Because weak destiny theorists, in contrast, do not tend to diagnose and evaluate the long-term prospects of their relationship on the basis of their immediate cognitive and affective experiences, they are unlikely, when evaluating the meaning of offenses, to draw long-term conclusions regarding whether it is safe for them to depend on their partner. Thus, they are unlikely to exhibit reduced forgiveness as a function of experiencing state attachment anxiety (vs. security). In contrast to varying along the destiny dimension, varying along the growth dimension is not associated with diagnostic tendencies regarding compatibility and future success and, therefore, is not expected to interact with state attachment anxiety to predict forgiveness. $^{2}$

\section{Attachment Representations}

Along with several other prominent perspectives (e.g., Holmes \& Rempel, 1989; Murray \& Holmes, 2000; Sullivan, 1953), attachment theory highlights the importance of satisfying the need for "felt security" (Sroufe \& Waters, 1977), which is a state that

\footnotetext{
${ }^{1}$ Although most research has examined the effects of growth and destiny beliefs separately, two empirical articles have reported analyses investigating their interactive effects, one as a central focus (Knee et al., 2001) and one as a peripheral focus (Franiuk et al., 2002). Given that (a) most extant research on implicit theories of relationships treats growth and destiny beliefs as independent dimensions, (b) growth beliefs and destiny beliefs are conceptually and (in general) statistically independent dimensions, and (c) we developed our hypotheses with regard to destiny beliefs in particular, we focus on the two-way interactions involving state attachment anxiety and either destiny or growth beliefs rather than on three-way interactions involving both of them.

${ }^{2}$ One might speculate that the orientation toward conflict resolution underlying strong (vs. weak) growth beliefs should lead to the prediction that such beliefs will exhibit a main effect with greater forgiveness. We did not advance such a prediction because we do not conceptualize strong growth theorists as doormats who will automatically forgive any offense. Rather, we view them as individuals who see merit in tackling relationship difficulties directly and who believe that successfully resolving such difficulties can strengthen the relationship even beyond where it was before the difficulties began (Knee, 1998). Such an approach, however, does not necessarily make them more forgiving; it merely orients them toward active conflict resolution.
} 
ensues when individuals are confident that their relationship partner will be responsive to their needs (Ainsworth, Blehar, Waters, \& Wall, 1978; Bowlby, 1982). The attachment system is activated when individuals perceive that there is a threat to their attachment security (Bowlby, 1982, Mikulincer \& Shaver, 2003), an experience that is likely when one is contemplating how to respond to offenses committed by a romantic partner. Most researchers agree that the attachment system varies along distinct dimensions of anxiety and avoidance, with low scores on these dimensions indicating attachment security (Ainsworth et al., 1978; Brennan, Clark, \& Shaver, 1998; Simpson, Rholes, \& Phillips, 1996). For example, experiencing low levels of attachment anxiety is equivalent to experiencing high levels of attachment security on the anxiety dimension.

Fraley and Shaver $(1998,2000)$ have argued that the anxiety dimension measures the affective and attributional processes involved in monitoring and appraising events for signs of threat, whereas the avoidance dimension measures the strategies individuals use to regulate their attachment needs. As discussed above, individuals experiencing strong anxiety tend to feel preoccupying uncertainty about whether their partner will be accepting versus rejecting toward them, and they tend to be buffeted around emotionally by relationship events and to catastrophize the anticipated future consequences of relationship difficulties (Campbell et al., 2005). Individuals experiencing strong attachment avoidance tend to deal with insecurity by orienting away from their partner; varying along the attachment avoidance dimension is associated neither with being buffeted around by relationship events nor with basing evaluations of future relationship quality on them (Campbell et al., 2005). Because anxiety, not avoidance, predicts the affective and attributional processes that are crucial for destiny theorists, the present research focused primarily on the anxiety dimension.

Building on Bowlby's (1973) theoretical work regarding "internal working models" and on Hazan and Shaver's (1987) seminal article applying Ainsworth et al.'s (1978) infant attachment typology to adult romantic relationships, the vast majority of researchers on adult romantic attachment have conceptualized these anxious and avoidant representations as stable individual difference variables. A substantial literature has now emerged, however, demonstrating that these representations can be (a) context-sensitive (state) rather than stable (trait) and (b) partner-specific rather than global. This literature is consistent with Collins and Allard's (2001) observations that although "internal working models of attachment are [typically] thought to be core features of personality" (p. 60), "individuals possess multiple models of attachment that differ in their level of specificity and accessibility" (p. 70).

Two lines of evidence demonstrate that contextual factors can influence individuals' attachment representations. First, laboratory studies in the social cognitive tradition have demonstrated that anxious, avoidant, and secure attachment representations can be primed experimentally (e.g., Baldwin, Keelan, Fehr, Enns, \& KohRangarajoo, 1996; Mikulincer, Shaver, Gillath, \& Nitzberg, 2005; see Baldwin, 1992). For example, participants primed (via an ostensible sentence memorization task) with attachment security exhibited stronger exploratory tendencies than did those primed with attachment anxiety or avoidance (Green \& Campbell, 2000). Second, longitudinal studies have revealed that individuals exhibit marked fluctuations in their attachment representations over time as a function of their life circumstances (e.g., Baldwin \& Fehr,
1995; Davila, Karney, \& Bradbury, 1999). In one study, participants completed daily diaries assessing their subjective construal of life events and their state attachment anxiety and avoidance for 56 consecutive days; multilevel modeling analyses revealed greater within-person than between-persons variability in these attachment representations, and the within-person variability was predicted in a theoretically sensible manner by individuals' subjective construals of daily life events (Davila \& Sargent, 2003). In the present article, we use the terms state attachment anxiety and/or avoidance to refer to context-sensitive (i.e., time varying) representations and trait attachment anxiety and/or avoidance to refer to stable representations.

Complementing this research suggesting that attachment representations can be context-sensitive is a separate literature emphasizing that individuals experience partner-specific attachment representations (Baldwin et al., 1996; Bartholomew \& Horowitz, 1991; Collins \& Read, 1994; Cook, 2000; La Guardia, Ryan, Couchman, \& Deci, 2000; Shaver, Collins, \& Clark, 1996; Treboux, Crowell, \& Waters, 2004). Results from one study revealed that partner-specific attachment measures were stronger predictors of diverse outcomes than were global measures, and this difference was especially robust for relationship-specific outcomes such as romantic love and relationship satisfaction (Cozzarelli, Hoekstra, \& Bylsma, 2000). Results from another study revealed that (a) global measures of attachment representations predicted a small proportion of the variance in measures of partner-specific representations and (b) partner-specific measures accounted for unique variance beyond global measures in predicting the quality and intimacy of interpersonal interactions (Pierce \& Lydon, 2001). ${ }^{3}$

Scholars' decisions about how to assess attachment representations (e.g., stable or context-sensitive, global or partner-specific) have important theoretical implications. Scholars might elect to use the conventional measurement approach of assessing attachment representations as stable and global dispositions, but this decision should be made after systematic consideration of the theoretical issues at play rather than as anconsidered default (see Cozzarelli et al., 2000). The present research provides one illustration of why the conventional measurement approach can sometimes fail to allow for adequate tests of certain theoretical questions. The central idea underlying this research is that strong (vs. weak) destiny theorists tend to diagnose the future of their relationship on the basis of the meaning they ascribe to their immediately available subjective experiences (attachment anxiety, in this case; Knee \& Canevello, 2006). As such, our hypotheses require that the attachment representations be accessible to participants at the time they respond to the offenses rather than assessed with a stable and global measure long before or long after experiencing them. Both studies reported herein investigate state attachment representations (which are global in Study 1 and partnerspecific in Study 2).

\footnotetext{
${ }^{3}$ This partner-specific approach to attachment representations is similar to many of the constructs investigated by Murray and her colleagues, especially anxiety about acceptance (sample item: " $[\mathrm{I}$ am] unsure whether [my] partner is happy in our relationship"; Murray, Bellavia, Rose, \& Griffin, 2003) and perceptions of the partner's [non]love (sample item: "Sometimes I wonder whether my partner feels as strongly for me as I feel for him or her"; Murray et al., 2005).
} 
We anticipated that state attachment avoidance (because it is unlikely to trigger diagnostic tendencies) would not interact with destiny beliefs to predict forgiveness, whereas state attachment anxiety (because it is likely to invigorate hyperactive attributional processes) would. Anxious attributional processes trigger insecurity-tinged evaluative processes for strong destiny theorists, ultimately causing them to become distrustful and unforgiving.

\section{Trust as a Mediator}

Adult attachment dynamics largely revolve around trust (Mikulincer, 1998), which is defined as individuals' positive expectation that "they can count on a partner to care for them and be responsive to their needs, now and in the future" (Holmes \& Rempel, 1989 , p. 188) - that it is worth the risks associated with being vulnerable for the promise of future benefits from the relationship. Such expectations, we suggest, are crucial in promoting forgiveness because they allow individuals to feel confident that forgiveness is likely to lead to enhanced relationship well-being. In contrast, individuals who are experiencing less trust closely evaluate their partner's behaviors to ascertain whether salutary relationship outcomes will be forthcoming (Holmes \& Rempel, 1989; Murray \& Holmes, 2000). Attachment anxiety not only predicts vigorous attempts to trust one's partner, it also predicts insecurities that frequently foil these efforts. Many empirical demonstrations have revealed that heightened attachment anxiety predicts distrust in relationship partners (e.g., Baldwin, Fehr, Keedian, Seidel, \& Thomson, 1993; Baldwin et al., 1996; Collins \& Read, 1990; Hazan \& Shaver, 1987; Mikulincer, 1998), likely because the anxiety predicts negative attributions about partners' distressing behavior (Collins, 1996; Whisman \& Allan, 1996). ${ }^{4}$ We argue that the diagnostic tendencies of strong destiny theorists amplify the significance of the preoccupying uncertainty associated with experiencing state attachment anxiety (vs. security) and render individuals especially vulnerable to distrusting their partner, which ultimately leads to reduced forgiveness. In contrast, weak destiny theorists who experience state attachment anxiety are unlikely to conclude that they will not be able to trust their partner in the future.

\section{Hypotheses and Research Overview}

The present article represents the first investigation into the interplay between implicit theories and attachment dynamics in predicting relationship outcomes. Our primary hypothesis is that destiny beliefs interact with state attachment anxiety to predict forgiveness tendencies. In particular, strong (vs. weak) destiny beliefs predict reduced forgiveness tendencies for individuals experiencing state attachment anxiety, but such beliefs exhibit no association with forgiveness for individuals experiencing state attachment security. Our secondary hypothesis is that the association of the Destiny Beliefs $\times$ State Attachment Anxiety interaction effect with forgiveness tendencies is mediated (at least in part) by the experience of trust in the partner.

We investigated our primary hypothesis in both studies and our secondary hypothesis in Study 2. In both studies, participants began by completing measures of destiny and growth beliefs and trait attachment anxiety and avoidance. In Study 1, they next experienced an experimental manipulation of (global) state attach- ment anxiety (vs. security) and then indicated the degree to which they would forgive a series of hypothetical partner offenses. In Study 2, they then reported every-other week for 6 months (14 waves in total) on (a) their naturally occurring fluctuations in (partner-specific) state attachment anxiety and avoidance, (b) their trust in their partner, (c) offenses committed by their romantic partner, and (d) their forgiving responses to those offenses. Both studies allowed us to avoid relying on participants' forgiveness reports from offenses perpetrated long ago and to examine the Destiny Beliefs $\times$ State Attachment Anxiety interaction effect after controlling for trait attachment representations. In addition, Study 2 allowed us to examine both (a) initial and delayed forgiveness in response to the same offense and (b) whether the Destiny Beliefs $\times$ State Attachment Anxiety interaction effect accounts for unique variance in forgiveness beyond the effects of numerous plausible confounding variables.

\section{Study 1}

\section{Method}

\section{Participants}

A sample of 145 Northwestern University undergraduates (89 women, 56 men) participated in partial fulfillment of the requirements of an introductory psychology course. Approximately half of the participants were Caucasian (54\% Caucasian, 24\% Asian American, $11 \%$ Black or African American, 6\% Hispanic or Latino, and $6 \%$ other/mixed), and nearly two thirds were single (66\% single, $7 \%$ dating casually, $27 \%$ dating seriously or engaged).

\section{Procedure and Materials}

Participants first completed measures of trait attachment anxiety, trait attachment avoidance, destiny beliefs, and growth beliefs on 1 (strongly disagree) to 7 (strongly agree) scales. The trait attachment scales were shortened, 5-item versions of previously validated, 18-item scales measuring each construct (Brennan et al., 1998). ${ }^{5}$ Both trait attachment anxiety (e.g., "I need a lot of reas- Fn5

\footnotetext{
${ }^{4}$ These studies used stable and global measures of attachment anxiety. Given the emerging corpus of evidence (reviewed above) suggesting that context-sensitive and/or partner-specific measures frequently predict attachment behavior in a manner compatible with stable and global measures, we expected that the association of attachment anxiety with distrust would also exist with context-sensitive measures, although previous research has not investigated this topic.

${ }^{5}$ Because of a procedural glitch, 27 participants failed to provide trait attachment information. Also, for the sake of an unrelated project, the instructions for these trait attachment measures differed slightly from the typical instructions. Specifically, participants were asked to report the degree to which they agreed with each statement in "long-term, established romantic relationships" (vs. the typical instructions, which simply ask about "romantic relationships"). Given that we were interested in assessing trait attachment anxiety regarding romantic relationships that attachment researchers typically conceptualize as "attachment relationships," we were comfortable using the slightly modified language to measure it in Study 1. We nonetheless used the typical instructions to measure trait attachment representations in Study 2.
} 
surance that I am loved by romantic partners," "I worry that romantic partners won't care about me as much as I care about them"; $\alpha=.85$ ) and trait attachment avoidance (e.g., "I find it difficult to allow myself to depend on romantic partners," "I turn to romantic partners for many things, including comfort and support" [reverse scored]; $\alpha=.68$ ) exhibited acceptable scale reliability. These trait attachment anxiety and avoidance measures were not significantly correlated $(r=-.07, p=.44)$. The destiny and growth beliefs scales were shortened, 4-item versions of previously validated, 11-item scales measuring each construct (Knee et al., 2003). Both destiny beliefs (e.g., "potential relationship partners are either compatible or they are not," "potential relationship partners are either destined to get along or they are not"; $\alpha=.70$ ) and growth beliefs (e.g., "a successful relationship evolves through hard work and resolution of incompatibilities," "it takes a lot of time and effort to cultivate a good relationship"; $\alpha=$ .73) exhibited acceptable scale reliability. These destiny beliefs and growth beliefs measures were weakly and negatively correlated $(r=-.15, p=.07)$.

After they completed these trait attachment and implicit theories of relationships measures, participants were randomly assigned to experience either the attachment anxiety prime or the attachment security prime (for examples of other experiments using priming procedures to manipulate attachment representations, see Baldwin et al., 1996; Green \& Campbell, 2000; Mikulincer et al., 2005). Adapting the scrambled sentence test priming procedure from the social cognition literature (Srull \& Wyer, 1979; see Bargh \& Chartrand, 2000), we presented participants with 10 different series of five words and instructed them to unscramble the words and eliminate one to make a four-word sentence. There was only one sensible four-word sentence that could be created for each series of five words. Participants crossed out the extra word and wrote out the correct sentence. They were provided with an example in which the word series banana ate yellow the he" was already unscrambled to read "he ate the banana."

This scrambled sentence test allowed us to incorporate our experimental manipulation of state attachment anxiety (vs. security). Although three filler-word series were the same in both conditions (e.g., she door walked the painted became "she painted the door"), the other seven differed between the attachment anxiety and the attachment security conditions. Whereas the anxiety word series were designed to activate representations related to uncertainty and vulnerability, the security word series were designed to activate representations of certainty and safety. For example, participants in the attachment anxiety condition unscrambled word series such as child vulnerable today felt the ("the child felt vulnerable"), was unreliable thought the mother ("the mother was unreliable"), and shiny devotion was their uncertain ("their devotion was uncertain"). In contrast, in the attachment security condition, the word vulnerable was changed to protected ("the child felt protected"), the word unreliable was changed to reliable ("the mother was reliable"), and the word uncertain was changed to certain ("their devotion was certain"). To reduce the likelihood of participants becoming suspicious about the interpersonal nature of these unscrambled sentences, we changed a few of the word series in content structure from these previous examples, but those series were also designed to prime anxiety and uncertainty versus safety and certainty (e.g., unsteady [steady] hands the boat was became "the boat was unsteady [steady]").
After unscrambling these 10 word series, participants indicated on a scale from 1 (I would not forgive at all) to 9 (I would forgive completely) the degree to which they would forgive a series of 12 hypothetical offenses committed by their (current or hypothetical) romantic partner (e.g., "your partner is flirtatious with his/her ex" and "your partner lies to you about something important"). Participants' responses to these offenses hung together well as a scale $(\alpha=.90)$, so we averaged them to create a single, 12-item measure of forgiveness.

\section{Results \\ Primary Hypothesis Tests}

To test our primary hypothesis that individuals who adhere strongly (vs. weakly) to destiny beliefs are less forgiving of partner transgressions when experiencing state attachment anxiety, whereas such individuals do not exhibit an association between destiny beliefs and forgiveness tendencies when experiencing state attachment security, we conducted a simultaneous multiple regression analysis predicting forgiveness from destiny beliefs, prime condition, and their interaction term. As depicted in Figure 1, the $\mathbf{F} 1$ Destiny Beliefs $\times$ Prime Condition interaction effect was significant, $\beta=-.17, t(136)=-2.00, p<.05$. Consistent with predictions, tests of simple slopes (Aiken \& West, 1991) revealed a nonsignificant association of destiny beliefs with forgiveness among individuals in the attachment security condition, $\beta=.03$, $t(68)=0.26, p=.80$, but a significant negative association among those in the attachment anxiety condition, $\beta=-.29, t(68)=$ $-2.54, p=.01$. The main effects for destiny beliefs and prime condition were not significant $(p s>.10){ }^{6}$

We performed two supplemental analyses to provide additional support for the hypothesis that our central effect is driven by the interaction of destiny beliefs and state (but not trait) attachment anxiety. First, we explored whether destiny beliefs would interact with trait attachment anxiety to predict forgiveness by replicating our primary analysis after substituting trait attachment anxiety for prime condition. This straightforward analysis predicted forgiveness from destiny beliefs, trait attachment anxiety, and their interaction term. As predicted, results revealed a nonsignificant Destiny Beliefs $\times$ Trait Attachment Anxiety interaction effect, $\beta=.11$, $t(113)=1.16, p=.25$. Second, in a particularly rigorous analysis, we replicated the primary analysis reported above after controlling for the effects of both trait attachment anxiety and trait attachment avoidance. As predicted, the Destiny Beliefs $\times$ Prime Condition

\footnotetext{
${ }^{6}$ We conducted two exploratory analyses to examine whether our effects were moderated by participant sex or by current relationship status (single, dating casually, or dating seriously). We added either the participant sex or the relationship status main effect and all three interaction effects (the two-way interactions with destiny beliefs and with prime conditions, and the three-way interaction). None of the six interaction effects tested across these two analyses was statistically significant, although the Destiny Beliefs $\times$ Prime Condition $\times$ Participant Sex analysis approached significance $(p=.08)$. This near-effect suggests that the Destiny Beliefs $\times$ State Attachment Anxiety interaction effect was possibly stronger for men than for women, although the direction of the effect was the same for both sexes. Given that (a) this interaction effect was unexpected, (b) the analysis was exploratory, and (c) the effect was marginal, we awaited the results of Study 2 before drawing conclusions about any possible sex differences.
} 


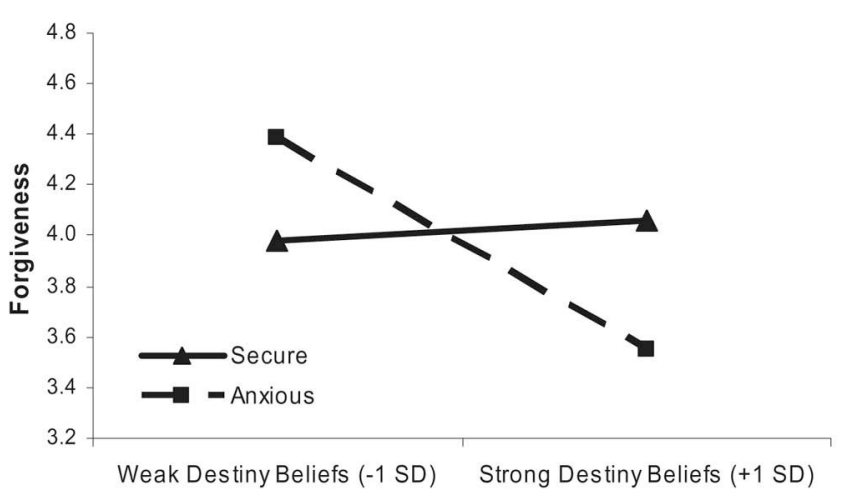

Figure 1. Study 1: Predicting forgiveness from destiny beliefs and the state attachment anxiety (vs. security) prime.

interaction effect remained significant, $\beta=-.19, t(111)=-2.03$, $p=.04$. This analysis also revealed a significant main effect of destiny beliefs, $\beta=-.22, t(111)=-2.36, p=.02$, and an unexpected, positive, and nearly significant main effect of trait attachment avoidance, $\beta=.17, t(111)=1.85, p=.07 .^{7}$ The main effects of prime condition and trait attachment anxiety were not significant $(p s>.10)$.

\section{Growth Beliefs-Exploratory Analyses}

As argued in the Introduction, we did not predict that growth beliefs would interact with state attachment anxiety to predict forgiveness because such beliefs are expected neither to be reactive to the threat and insecurity associated with attachment anxiety nor to cause individuals to diagnose the long-term prospects for their relationship when dealing with upsetting partner behavior in the present. For exploratory purposes, however, we replicated the primary analysis reported above, this time replacing destiny beliefs with growth beliefs. As predicted, this analysis revealed nonsignificant effects for growth beliefs, prime condition, and their interaction term $(p s>.10)$.

\section{Discussion}

The results of Study 1, then, reveal strong support for the hypothesis that destiny beliefs are negatively associated with forgiveness for individuals experiencing state attachment anxiety but are not associated with forgiveness for individuals experiencing state attachment security. The experimental manipulation of state attachment anxiety (vs. security) provides compelling evidence that individuals characterized by strong destiny beliefs tend to catastrophize the meaning of romantic offenses-but only when making forgiveness decisions while experiencing state attachment anxiety. In addition, the analysis controlling for trait attachment representations provides especially strong evidence for our theoretical analysis, and using hypothetical offenses provides excellent experimental control over the precise interpersonal dynamics to which individuals are responding.

Study 1 , however, suffers from a number of limitations. First, although the use of hypothetical offenses allows for superb experimental control, such offenses are unlikely to arouse the intensity of affective and cognitive responses experienced in the wake of naturally occurring offenses. Second, it is possible that the experimental manipulation of state attachment anxiety (vs. security) used in Study 1 fails to characterize the real-world fluctuations that individuals experience in their everyday lives. Third, Study 1 only assessed forgiveness at one point in time, which means that we could not examine the associations of destiny beliefs and state attachment anxiety with forgiveness over time. Fourth, more than half of the participants in Study 1 were not currently involved in a romantic relationship. Although no evidence emerged to suggest that the conclusions of the above analyses were moderated by relationship status (see Footnote 6), it would be valuable to replicate the Destiny Beliefs $\times$ State Attachment Anxiety interaction effect in a sample in which all participants responded to offenses in their current romantic relationship. Fifth, the Study 1 procedures do not allow for tests of whether destiny beliefs interact with state attachment avoidance to predict forgiveness tendencies; such interaction effects were not predicted but should be investigated nonetheless. Sixth and finally, the procedures used in Study 1 did not allow us to examine whether the association of this interaction effect with forgiveness was significantly mediated through the experience of trust in the partner.

\section{Study 2}

To address these limitations of Study 1, we conducted Study 2, which was a 14-wave longitudinal study in which participants reported every-other week for 6 months on (a) their state attachment anxiety, (b) their trust in their partner, (c) offenses committed by their romantic partner, and (d) their forgiving responses to those offenses. In an initial questionnaire preceding this 14-wave study, participants completed measures assessing their destiny and growth beliefs and their trait attachment anxiety and avoidance. We examined whether the Destiny Beliefs $\times$ State Attachment Anxiety interaction effect predicts forgiveness tendencies, not only in relatively simple analyses but also after controlling for the effects of numerous plausible confounding variables.

\section{Method}

\section{Participants and Recruitment}

A sample of 69 Northwestern University freshmen (35 women, 34 men) were recruited to participate in a 6-month longitudinal study of dating processes via flyers posted around campus. Eligibility criteria required that each participant must be (a) a 1st-year undergraduate at Northwestern University, (b) involved in a dating relationship of at least 2 months in duration, (c) between 17 and 19 years old, (d) a native English speaker, and (e) the only member of a given couple to participate in the study. Participants who completed all components of the study were paid $\$ 100$; those who missed some were paid a prorated amount. Participant retention

\footnotetext{
${ }^{7}$ This marginal trait attachment avoidance effect does not emerge in a correlational analysis examining its simple association with forgiveness $(p=.18)$, and it contradicts findings from previous research (e.g., Brown \& Phillips, 2005). If this effect fails to replicate in Study 2, we believe that the most sensible conclusion is that it is nothing more than a one-time data hiccup.
} 
was excellent: All 69 participants completed the study, and 67 of them completed at least 12 of the 14 online measures.

At the beginning of the study, most participants were 18 years old $(7 \%$ were $17,81 \%$ were 18 , and $12 \%$ were 19$)$, Caucasian (74\% Caucasian, 12\% Asian American, 3\% Hispanic, 1\% African American, and $10 \%$ other), and had been involved with their dating partners for an average of 13.05 months $(S D=9.76)$. During the 6-month study, 26 participants broke up with their romantic partner; 18 of these had started dating somebody new before the study was over. Given that this study explored forgiveness processes in ongoing romantic relationships, participants only responded to the forgiveness measures if they were currently romantically involved. Eleven participants were excluded from all analyses because they did not experience any partner offenses during the course of the study and were consequently unable to report on forgiveness processes; this left our final sample at 58 participants.

\section{Procedure and Materials}

The present study was part of a larger investigation of dating processes that was divided into four parts: (a) an initial, hour-long questionnaire sent via campus mail, (b) a 90-min lab-based session involving additional questionnaires and training for the online sessions, (c) a 10- to 15-min online questionnaire every-other week for 6 months (14 in total), and (d) an hour-long lab-based session at the end of the 6-month period. All items were assessed on scales ranging from 1 (disagree strongly) to 7 (agree strongly). Given that participants were slated to respond to a nearly identical online questionnaire 14 times in 6 months (Part c), we streamlined the study by assessing our constructs of interest with brief measures ranging from 1 to 3 items, potentially diminishing the likelihood of detecting significant effects.

Independent variables. As part of the initial questionnaire, participants completed one validated, 11-item measure assessing destiny beliefs $(\alpha=.85)$ and another assessing growth beliefs $(\alpha=.80$; Knee et al., 2003). These two measures were not significantly correlated $(r=-.12, p=.35)$. As part of the initial the questionnaire, participants also completed 18-item measures of trait attachment anxiety $(\alpha=.92)$ and trait attachment avoidance $(\alpha=.95$; Brennan et al., 1998). These two measures were also not significantly correlated $(r=.14, p=.27)$. These implicit theories and attachment measures were the full-length versions of abbreviated scales from Study 1.

As part of the 14 biweekly online questionnaires, participants completed one-item measures assessing the degree to which they were experiencing partner-specific state attachment anxiety ("I need a lot of reassurance that my partner cares about me") and state attachment avoidance ("I feel comfortable opening up to my partner," [reverse scored]). We adapted these items from the scales described above (Brennan et al., 1998) because they captured the essence of each construct and translated nicely to a relationshipspecific context. A multilevel regression analysis predicting state attachment anxiety from state attachment avoidance revealed no evidence that these variables were associated, $\beta=.02, t(136)=$ $0.37, p=.71$. Our partner-specific measure of state attachment anxiety is similar to Murray and colleagues' measures of anxiety about acceptance (Murray et al., 2003) and perceptions of the partner's [non]love (Murray et al., 2005; see Footnote 30.
To provide evidence that these one-item measures of state attachment anxiety (the need for reassurance measure) and avoidance (the comfortable opening up measure [reverse scored]) serve as good proxies for the full-length versions of their respective scales, we conducted a pilot study in which we asked 265 undergraduate students at Virginia Commonwealth University to complete the full 18-item measures (adapted from Brennan et al., 1998) of both partner-specific attachment anxiety and partner-specific attachment avoidance regarding their current romantic partner. Results revealed that the "need for reassurance" item exhibited an item-total correlation of .63 with the 18 -item version of the scale, and dropping this item from the 18 -item scale resulted in a reduction in the scale's reliability. A similar pattern of results emerged for the 1-item "comfortable opening up" measure (although the original Brennan et al., 1998, measure, which we used in our pilot study, was framed in terms of discomfort with opening up): It exhibited an item-total correlation of .59 with the 18 -item version of the scale, and dropping this item from the 18-item scale resulted in a reduction in the scale's reliability. The results from this pilot study suggest that the 1-item measures used in Study 2 (which were used to avoid overburdening the participants) serve as good proxies for the full-length, partner-specific versions of the Brennan et al. (1998) measures. ${ }^{8}$

In sum, because we were interested in how general theories of relationships interact with state-level attachment representations to predict forgiveness tendencies, we assessed (a) implicit theories of relationships and trait attachment representations on the initial questionnaire (before the 14-wave online questionnaire part of the procedure began) and (b) state attachment representations on each of the 14 online questionnaires.

Dependent variables. On each of the biweekly online questionnaires, participants who were currently involved in a romantic relationship answered "yes" or "no" to the following question: "Has your partner done anything over the past two weeks that was upsetting to you?" If participants answered no, they moved on to an unrelated set of questions. If they answered yes, they provided a brief description of what their partner had done to upset them and then responded to several additional questions about the upsetting incident. Based on prominent theoretical approaches to forgiveness emphasizing the importance of greater benevolence motivation in conjunction with lesser revenge and avoidance motivations (Fincham et al., 2004; McCullough \& Hoyt, 2002), we assessed initial forgiveness with a three-item measure designed to assess these motivations ("I have forgiven my partner for this behavior," "I am tempted to 'get back at' my partner for this behavior" [reverse scored], and "I am tempted to keep distance from my partner as a result of this behavior" [reverse scored]; $\alpha=.71$ ).

\footnotetext{
${ }^{8}$ Three additional reasons support the use of these one-item measures. First, adult attachment researchers are converging on the consensus that attachment anxiety is a unidimensional construct, which suggests that any given item from the scale should represent an exemplar of the entire scale (e.g., Brennan et al., 1998; Simpson et al., 1996). Second, statistical investigations have provided compelling evidence that one-item measures provide reasonable proxies for their full scales (e.g., Wanous \& Hudy, 2001; Wanous, Reichers, \& Hudy, 1997). And third, an analysis using our primary (not pilot) data set revealed a hefty .69 correlation between trait attachment anxiety (assessed once at the beginning of the study) and the mean of the 14 assessments of state attachment anxiety.
} 
If participants reported an upsetting partner behavior 2 weeks before a given wave (i.e., at the previous wave), they again indicated the degree to which they agreed with the straightforward, face-valid item, "I have forgiven my partner for this behavior." Using this identical measure at two points in time allows us to explore not only whether the Destiny Beliefs $\times$ State Attachment Anxiety interaction effect predicts forgiveness, but also whether this effect emerges in predicting delayed forgiveness after controlling for the effect of earlier forgiveness. In all analyses predicting delayed forgiveness, we controlled for the one-item measure of earlier forgiveness; such analyses provide a strict measure of change over time by (a) using the identical measure at both time points and (b) minimizing the effects of memory bias (e.g., misremembering the offense as more minor than it was initially experienced) by providing the participants' with their own verbatim description of the offense, which they had provided 2 weeks earlier.

Putative mediator. Our secondary hypothesis states that the association of the Destiny Beliefs $\times$ State Attachment Anxiety interaction effect with forgiveness is significantly mediated through the experience of trust in the partner. We assessed trust on each online questionnaire with a face-valid, one-item measure: "I trust my partner."10

Potential confounds. To rule out several alternative explanations for any significant effects that might emerge, we measured eight potential confounds (in addition to the measures of trait attachment anxiety and trait attachment avoidance), five from the online questionnaires and three from the initial questionnaire. With one-item measures on the online questionnaires, we assessed two characteristics of the offense, time since the offense ("How many days ago did this behavior take place?") and offense severity ("This behavior was highly upsetting to me"), and two characteristics of the romantic relationship, relationship commitment ("I am committed to maintaining this relationship in the long run") and relationship closeness ("I feel 'close' to my partner"). To control for the previously identified effect that destiny beliefs interact with relationship closeness to predict relationship outcomes (such that feeling close to one's partner is a stronger predictor of relationship outcomes for strong than for weak destiny theorists; Knee, 1998), we included not only the relationship closeness main effect but also the Destiny Beliefs $\times$ Relationship Closeness interaction effect. Although finding evidence that the Destiny Beliefs $\times$ State Attachment Anxiety interaction effect predicts forgiveness tendencies after controlling for the Destiny Beliefs $\times$ Relationship Closeness interaction effect would not be equivalent to controlling for all previous effects that have ever been demonstrated in the implicit theories of relationships literature, it would provide strong support that the interaction effect involving state attachment anxiety functions independently of a central effect in that literature.

We assessed a measure of trait forgiveness and two trait tendencies toward socially desirable responding on the initial questionnaire. The previously validated four-item measure of trait forgiveness (e.g., "I have a tendency to harbor grudges" [reverse scored], "I tend to get over it quickly when someone hurts my feelings"; Brown, 2003) was reliably assessed in the present study $(\alpha=.82)$. The socially desirable responding measures of selfdeception (e.g., "I never regret my decisions") and impression management (e.g., "I am a completely rational person") were assessed with an abbreviated version of the Balanced Inventory of
Desirable Responding (Paulhus, 1984). For time efficiency, we shortened the original 20 -item subscales to 10 items each by excluding the 10 items with the lowest item-total correlations. Building on the original scoring protocol suggested for these scales (Paulhus, 1984), we scored items on which a given participant answered toward the extreme end of the scale (6 or 7 for the regularly scored items; 1 or 2 for the reverse-scored items) as a 1 ; otherwise, they were scored as a zero. The items for each subscale were then summed to provide a measure that could hypothetically range from 0 to 10 . Scale reliabilities were acceptable for selfdeception $(\alpha=.70)$ and somewhat low for impression management $(\alpha=.56)$.

\section{Analysis Strategy}

We used multilevel data analytic strategies (cf. Raudenbush \& Bryk, 2002) that researchers have adapted for analyzing diary data (e.g., Bolger, Davis, \& Rafaeli, 2003; Nezlek, 2001). The twolevel data structure included measures assessed on each of the online questionnaires (Level 1) nested within each participant (Level 2). For example, a participant who reported on three offenses provided three different associations between destiny beliefs, state attachment anxiety, and forgiveness. These nested observations violate the ordinary least squares regression assumption of independence. Multilevel modeling approaches provide unbiased hypothesis tests by simultaneously examining variance associated with each level of nesting.

Our statistical models specify that each person in the population has his or her own characteristic association of the Destiny Beliefs $\times$ State Attachment Anxiety interaction effect with forgiveness. The model for the cross-sectional analysis predicting initial forgiveness is as follows:

$$
F_{i t}=\beta_{0}+\beta_{1}\left(D_{i}\right)+\beta_{2}\left(S_{A n x}\right)+\beta_{3}\left(D B B_{i} \times S A n x_{i t}\right)+r_{i t},
$$

where $F_{i t}$ is the forgiveness score for individual $i$ at time $t, D B_{i}$ is the destiny beliefs score for individual $\mathrm{i}, \mathrm{SAnx}_{\mathrm{it}}$ is the state attachment score for individual $i$ at time $t$, and $r_{i t}$ is a residual component in the forgiveness score for individual $i$ at time $t$. The model for the longitudinal analysis predicting delayed forgiveness is the following:

$$
\begin{aligned}
F_{i t}=\beta_{0}+\beta_{1}\left(D B B_{i}\right)+\beta_{2}\left(S_{A n x}\right)+\beta_{3}( & \left.D B B_{i} \times S A n x_{i t}\right) \\
& +\beta_{4}\left(F_{i, t-1}\right)+r_{i t},
\end{aligned}
$$

where the only new term $\left(\mathrm{F}_{\mathrm{i}, \mathrm{t}-1}\right)$ is the earlier forgiveness score regarding the same offense for individual $i$ at time $t-1$ ( 2 weeks

\footnotetext{
${ }^{9}$ We selected this item for the follow-up assessment because of its face validity. Participants did not complete the revenge and avoidance items again at the follow-up because the possibility that participants would be answering questions about a new offense and a previous offense-not to mention a slew of additional items unrelated to the present report-in the same session left us concerned that the questionnaire was in danger of becoming prohibitively onerous.

${ }^{10}$ The within-wave Pearson product-moment correlation between trust and state attachment anxiety ranged across the 14 waves from -.50 to +.01 , with a mean correlation across the 14 waves of -.26 . Given that the average correlation between these two constructs is in the small to moderate range, there is clear evidence that they are empirically differentiable.
} 
before the present assessment). Because this analysis controls for earlier forgiveness in predicting delayed forgiveness, it allows us to examine whether the Destiny Beliefs $\times$ State Attachment Anxiety interaction effect predicts changes in forgiveness over time. This analysis includes the concurrent measure of state attachment anxiety $\left(\mathrm{SAnx}_{\mathrm{it}}\right)$ rather than the one assessed 2 weeks earlier $\left(\mathrm{SAnx}_{\mathrm{i}, \mathrm{t}-1}\right)$ because our theoretical emphasis pertains to destiny theorists' tendency to diagnose the potential of their relationship on the basis of the information that is immediately available (e.g., state attachment anxiety; see Knee \& Canevello, 2006). In the interest of comprehensiveness, however, we also perform a supplemental analysis examining the statistical model in Equation 2 after substituting in $\mathrm{SAnx}_{\mathrm{i}, \mathrm{t}-1}$ for $\mathrm{SAnx} \mathrm{x}_{\mathrm{it}}$.

Two additional features of the Study 2 analysis strategy warrant comment. First, we tested a number of additional models (e.g., a series of cross-sectional and longitudinal models controlling for various possible confound variables). Although we do not provide the relevant equations due to space constraints, they are straightforward extensions of the models presented in Equations 1 and 2. Second, following the data analytic advice of Kenny, Mannetti, Pierro, Livi, and Kashy (2002) for circumstances in which there are small numbers of Level 1 associations nested within each Level 2 unit (as is true in the present research), we allowed intercept terms to vary randomly and treated slope terms as fixed in all analyses.

\section{Results}

On average, participants reported $3.38(S D=2.65)$ offenses during the course of the study (although the mean would have been 2.86 if the 11 participants who reported 0 offenses had been included), and these offenses were moderately to highly upsetting $(M=5.23, S D=1.49)$.

\section{Primary Hypothesis Tests}

To test the hypothesis that strong (vs. weak) destiny beliefs predict reduced forgiveness tendencies for individuals experiencing state attachment anxiety, but that such beliefs exhibit no association with forgiveness for individuals experiencing state attachment security, we conducted a cross-sectional multilevel regression analysis predicting initial forgiveness and a longitudinal one predicting delayed forgiveness. ${ }^{11} \mathrm{We}$ first regressed our measure of initial forgiveness on our measures of destiny beliefs, state attachment anxiety, and their interaction term. The results of this analysis are depicted in Figure 2. The Destiny Beliefs $\times$ State Attachment Anxiety interaction effect was significant, $\beta=-.16$, $t(132)=-2.35, p=.02$. Consistent with predictions, tests of simple slopes conditioned 1 standard deviation above and below the means of state attachment anxiety and of destiny beliefs (Aiken $\&$ West, 1991) revealed a nonsignificant association of destiny beliefs with initial forgiveness among individuals experiencing state attachment security (i.e., low anxiety), $\beta=.08, t(132)=$ $0.77, p=.44$, but a significant negative association among individuals experiencing state attachment anxiety (i.e., high anxiety), $\beta=-.24, t(132)=-1.97, p=.05$. This analysis also revealed a nonsignificant main effect for destiny beliefs, $\beta=$ $-.08, t(132)=-0.89, p=.37$, but a significant main effect for

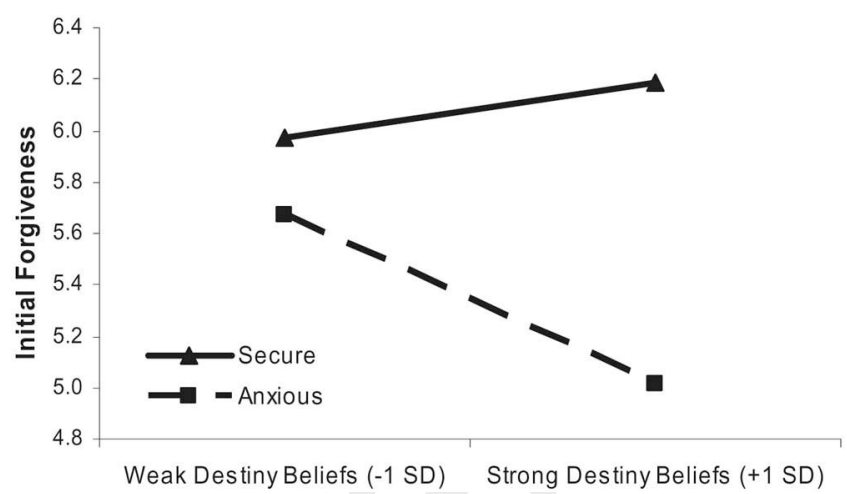

Figure 2. Study 2: Predicting initial forgiveness from destiny beliefs and state attachment anxiety.

state attachment anxiety, $\beta=-.27, t(132)=-3.74, p<.001$ : Greater state attachment anxiety predicted less forgiveness.

Next, we regressed our measure of delayed forgiveness on our measures of destiny beliefs, state attachment anxiety, and their interaction term-controlling for the measure of earlier forgiveness. As depicted in Figure 3, despite the strong stability effect F3 predicting delayed forgiveness from earlier forgiveness, $\beta=.38$, $t(109)=5.05, p<.001$, the Destiny Beliefs $\times$ State Attachment Anxiety interaction effect significantly predicted delayed forgiveness, $\beta=-.16, t(109)=-1.98, p<.05$. The tests of simple slopes conditioned 1 standard deviation above and below the means of state attachment anxiety and of destiny beliefs were less conclusive than those from Study 1 and from the cross-sectional analyses in Study 2. As such, we performed an additional set of simple slope analyses, this time conditioning the destiny beliefs slopes 2 standard deviations above and below the mean of state attachment anxiety to examine the associations of destiny beliefs with forgiveness for individuals experiencing especially strong state attachment anxiety or security. These tests revealed an unexpected (nearly significant) positive association of destiny beliefs with delayed forgiveness among individuals experiencing state attachment security, $\beta=.30, t(109)=1.74, p=.08$, and the expected (nearly significant) negative association among individuals experiencing state attachment anxiety, $\beta=-.32, t(109)=$ $-1.74, p=.08$. In short, the simple effects for the longitudinal analysis predicting change over time in forgiveness were (perhaps not surprisingly) somewhat weaker than those from the crosssectional analysis, although results did reveal (with near significance) the predicted negative association between destiny beliefs and forgiveness among individuals experiencing especially strong state attachment anxiety.

\footnotetext{
${ }^{11}$ As in Study 1, we conducted an additional analysis to examine whether our effects were moderated by participant sex. Results from these exploratory analyses indicated that the Destiny Beliefs $\times$ Participant Sex, State Attachment Anxiety $\times$ Participant Sex, and Destiny Beliefs $\times$ State Attachment Anxiety $\times$ Participant Sex analyses were not statistically significant $(p s>.10)$, so we collapsed across participant sex in all analyses. Taken together, the results from Studies 1 and 2 provide no compelling evidence that any of our central effects are moderated by participant sex.
} 


\begin{tabular}{|l|l|l|l|l|l|}
\hline tapraid5/z2g-perpsy/z2g-perpsy/z2g00507/z2g3104d07g & gockleyj & S=5 & 2/20/07 & 14:17 & Art: 2005-0978-RR \\
\hline
\end{tabular}

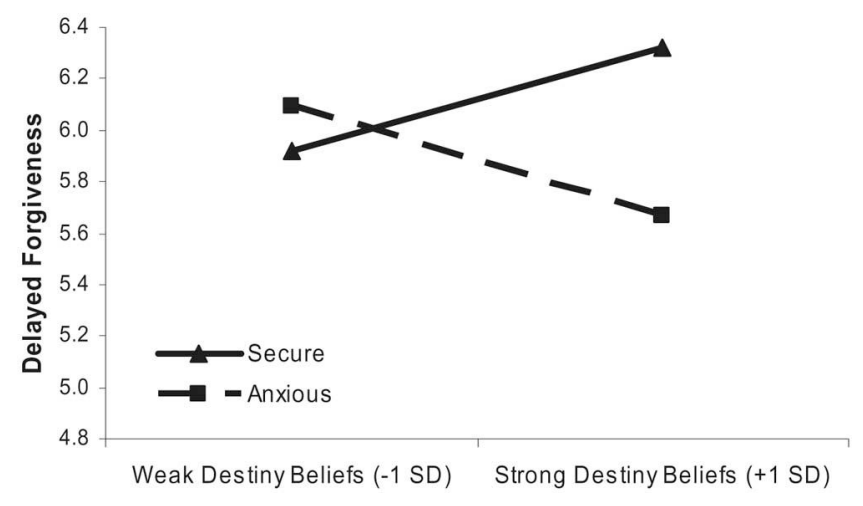

Figure 3. Study 2: Predicting delayed forgiveness from destiny beliefs and state attachment anxiety, controlling for earlier forgiveness.

As in Study 1, we explored whether destiny beliefs would interact with trait attachment anxiety to predict forgiveness by replicating our simple, primary analysis after substituting trait attachment anxiety for state attachment anxiety. These straightforward analyses predicted initial forgiveness from destiny beliefs, trait attachment anxiety, and their interaction term; the analysis predicting delayed forgiveness also controlled for earlier forgiveness. As predicted, these analyses revealed nonsignificant Destiny Beliefs $\times$ Trait Attachment Anxiety interaction effects in both the cross-sectional, $\beta=-.14, t(135)=-1.44, p=.15$, and longitudinal, $\beta=-.07, t(112)=-0.62, p=.53$, analyses. In parallel analyses, we also examined whether destiny beliefs would interact with the 1-item need for reassurance measure (rather than with the full 18-item measure) of trait attachment anxiety, and results once again revealed nonsignificant interaction effects in both the crosssectional, $\beta=-.13, t(135)=-1.30, p=.20$, and longitudinal, $\beta=.03, t(112)=0.27, p=.79$, analyses.

We also replicated the primary analyses predicting, respectively, initial forgiveness and delayed forgiveness after substituting state attachment avoidance for state attachment anxiety. As predicted, these analyses revealed nonsignificant Destiny Beliefs $\times$ State Attachment Avoidance interaction effects in both the crosssectional, $\beta=-.01, t(132)=-0.15, p=.88$, and longitudinal, $\beta=.07, t(109)=1.19, p=.24$, analyses.

\section{Ruling Out Alternative Explanations}

The analyses reported above provide compelling evidence that individuals who strongly subscribe to destiny beliefs and experience state attachment anxiety tend to be unforgiving of offenses perpetrated by their romantic partners and that these vengeful tendencies persist over time. We followed a two-step procedure to rule out plausible alternative explanations for the cross-sectional results. First, we conducted a simultaneous multilevel regression analysis examining the association of the Destiny Beliefs $\times$ State Attachment Anxiety interaction effect with initial forgiveness after controlling for trait attachment anxiety, trait attachment avoidance, and trait forgiveness; this analysis also included the destiny beliefs and state attachment anxiety main effects (as do all of the confound analyses to follow). As predicted, results revealed that the Destiny Beliefs $\times$ State Attachment Anxiety interaction effect remained significant, $\beta=-.18, t(132)=-2.67, p<.01$. This analysis also revealed significant (or nearly significant) main effects of state attachment anxiety, $\beta=-.20, t(132)=-2.52, p=$ .01 , and trait forgiveness, $\beta=.17, t(132)=1.93, p=.06$, but nonsignificant associations for the other three effects (destiny beliefs, trait attachment anxiety, and trait attachment avoidance; $p$ s $>.10)$.

Second, we conducted a particularly conservative simultaneous multilevel regression analysis examining the association of the Destiny Beliefs $\times$ State Attachment Anxiety interaction effect with initial forgiveness after controlling for the following 10 confound terms: trait attachment anxiety, trait attachment avoidance, trait forgiveness tendencies, self-deception, impression management, time since the offense, offense severity, relationship commitment, relationship closeness, and the Destiny Beliefs $\times$ Relationship Closeness interaction effect that had been previously identified (Knee, 1998) as a predictor of relationship outcomes. This rigorous test revealed that the Destiny Beliefs $\times$ State Attachment Anxiety interaction effect remained significant, $\beta=$ $-.14, t(126)=-2.26, p=.03$, an effect that emerged after controlling for the significant (or nearly significant) effects of trait forgiveness, $\beta=.13, t(126)=1.64, p=.10$, time since the offense, $\beta=.11, t(126)=2.25, p=.03$, offense severity, $\beta=$ $-.14, t(126)=-2.71, p<.01$, relationship commitment, $\beta=.26$, $t(126)=3.43, p<.001$, the relationship closeness main effect, $\beta=.25, t(126)=3.38, p=.001$, and the Destiny Beliefs $\times$ Relationship Closeness interaction effect, $\beta=-.11, t(126)=$ $-2.05, p=.04$-and for the nonsignificant effects of trait attachment anxiety, trait attachment avoidance, self-deception, and impression management ( $p s>.10)$. As in the cross-sectional analysis performed without including the confounds, the state attachment anxiety main effect was significant, $\beta=-.19$, $t(126)=-2.77, p<.01$, but the destiny beliefs main effect was $\operatorname{not}(p>.10)$.

We followed the same two-step procedure to rule out plausible alternative explanations for the longitudinal effects, with these analyses also controlling for the report of forgiveness 2 weeks earlier. We first conducted a simultaneous multilevel regression analysis examining the association of the Destiny Beliefs $\times$ State Attachment Anxiety interaction effect with delayed forgiveness after controlling for trait attachment anxiety, trait attachment avoidance, trait forgiveness, and earlier forgiveness. As predicted, results revealed that the Destiny Beliefs $\times$ State Attachment Anxiety interaction effect remained significant, $\beta=-.18$, $t(109)=-2.27, p=.03$. This analysis also revealed that the main effect of earlier forgiveness was significant, $\beta=.36, t(109)=$ $4.78, p<.001$, but the other five effects were not $(p \mathrm{~s}>.10)$.

We then conducted a particularly conservative simultaneous multilevel regression analysis examining the association of the Destiny Beliefs $\times$ State Attachment Anxiety interaction effect with delayed forgiveness after controlling for the effects of all of the confound terms included in the most conservative crosssectional analysis reported above-and for the effects of earlier forgiveness (11 confound terms in total). This rigorous test revealed that the Destiny Beliefs $\times$ State Attachment Anxiety interaction effect remained (nearly) significant, $\beta=-.14, t(104)=$ $-1.92, p=.06$, an effect that emerged after controlling for the significant (or nearly significant) effects of earlier forgiveness, $\beta=.34, t(104)=4.53, p<.001$, impression management, $\beta=$ 
$.16, t(104)=1.91, p=.06$, the relationship closeness main effect, $\beta=.23, t(104)=2.57, p=.01$, and (replicating Knee's, 1998, findings) the Destiny Beliefs $\times$ Relationship Closeness interaction effect, $\beta=-.16, t(104)=2.15, p=.03$-and for the nonsignificant effects of trait attachment anxiety, trait attachment avoidance, trait forgiveness, self-deception, time since the offense, offense severity, and relationship commitment ( $p$ s $>.10)$. As in the longitudinal analysis performed without including all of the additional confounds, the state attachment anxiety and destiny beliefs main effects were not significant ( $p$ s $>$.10). In short, even in these particularly conservative analyses, the Destiny Beliefs $\times$ State Attachment Anxiety interaction effect predicted both initial and delayed forgiveness tendencies.

For the theoretical reasons discussed above (see Analysis Strategy section), the primary longitudinal analyses predicting delayed forgiveness from state attachment anxiety, destiny beliefs, the interaction of these two terms, and earlier forgiveness-and the confound analyses presented in the preceding paragraphsincluded the concurrent measure of state attachment anxiety $\left(\mathrm{SAnx}_{\mathrm{it}}\right)$ rather than the one $\left(\mathrm{SAnx}_{\mathrm{i}, \mathrm{t}-1}\right)$ assessed 2 weeks earlier. We replicated the primary longitudinal analysis and both longitudinal confound analyses after substituting in the earlier measure of state attachment anxiety for the concurrent one. Replicating all results, analyses using the earlier measure revealed significant (or nearly significant) Destiny Beliefs $\times$ State Attachment Anxiety interaction effects, $\beta \mathrm{s}=-.12$ to $-.13, t \mathrm{~s}(104$ to 110$)=-1.70$ to $-1.96, p \mathrm{~s}=.05$ to .09 .

\section{Mediation by Trust?}

To test whether trust mediates (at least partially) the association of the Destiny Beliefs $\times$ State Attachment Anxiety interaction effect with forgiveness, we performed cross-sectional and longitudinal analyses following the standard four-step procedure presented by Baron and Kenny (1986; also see Kenny, Kashy, \& Bolger, 1998). Results from the cross-sectional analyses are de- forgiveness onto destiny beliefs, state attachment anxiety, and their interaction term. As presented above and in Figure 2, this analysis revealed a significant effect for the interaction term. In Step 2, we simultaneously regressed trust onto destiny beliefs, state attachment anxiety, and their interaction term. This analysis revealed that the interaction effect significantly predicted trust, $\beta=-.21$, $t(134)=-3.12, p<.01$. In Step 3, we simultaneously regressed initial forgiveness onto destiny beliefs, state attachment anxiety, their interaction term, and trust. This analysis revealed that trust significantly predicted initial forgiveness, $\beta=.45, t(130)=6.49$, $p<.001$, and that the interaction effect was no longer significant after including trust in the model, $\beta=-.10, t(130)=-1.59, p=$ .11. In Step 4, results from the modified Sobel (1982) test revealed evidence consistent with the hypothesis that trust significantly but partially mediates the association of the Destiny Beliefs $\times$ State Attachment Anxiety interaction effect with initial forgiveness $(z=$ $-2.84, p<.01)$.

Next, we performed these same four steps for the longitudinal analyses, the results of which are depicted in Figure 5. In F5 Step 1, we simultaneously regressed delayed forgiveness onto destiny beliefs, state attachment anxiety, their interaction term, and initial forgiveness. As presented above and in Figure 3, this analysis revealed a significant effect for the interaction term. In Step 2, we simultaneously regressed trust onto destiny beliefs, state attachment anxiety, and their interaction term. This analysis revealed that the interaction effect significantly predicted trust, $\beta=-.20, t(117)=-2.40, p=.02$. In Step 3, we simultaneously regressed delayed forgiveness onto destiny beliefs, state attachment anxiety, their interaction term, trust, and initial forgiveness. This analysis revealed that trust significantly predicted delayed forgiveness, $\beta=.27, t(107)=3.52$, $p<.001$, and that the interaction effect was no longer significant after including trust in the model, $\beta=-.12, t(107)=$ $-1.59, p=.11$. In Step 4, results from the modified Sobel (1982) test revealed evidence consistent with the hypothesis that trust significantly but partially mediates the association of

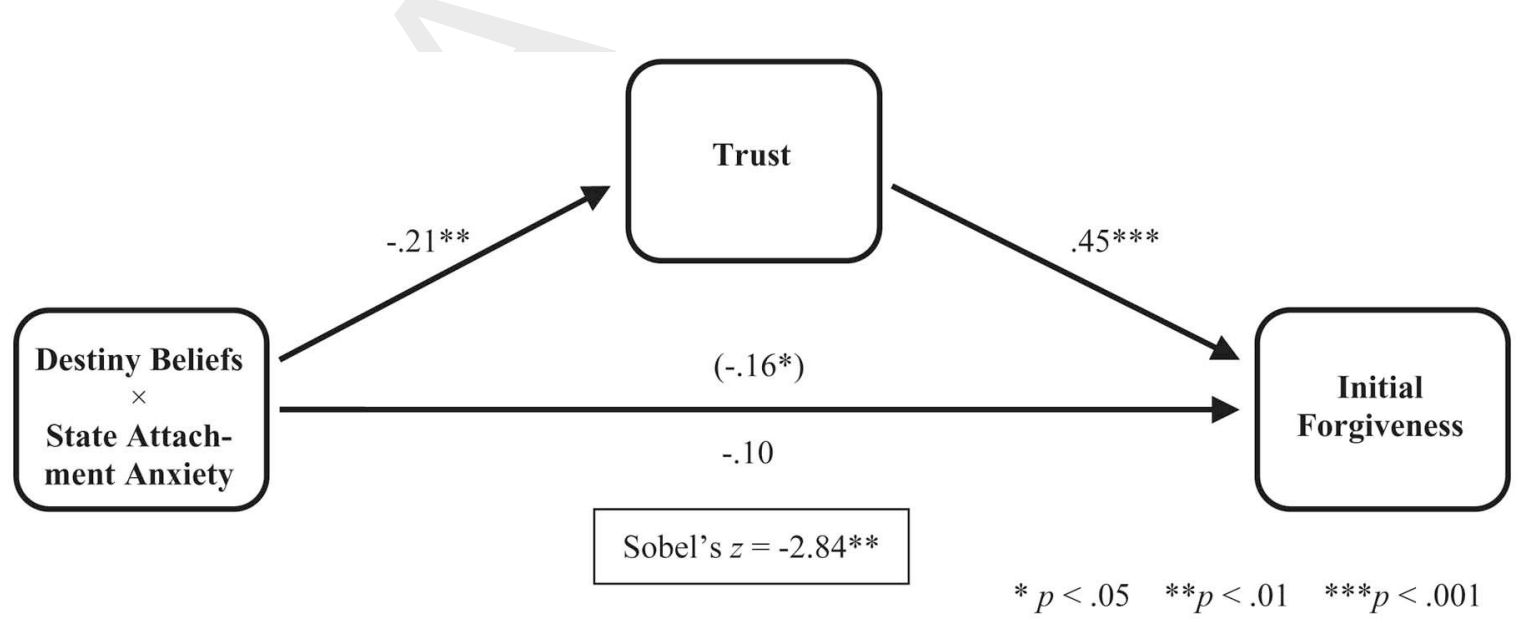

Figure 4. Study 2: Examining whether trust significantly mediates the association of the Destiny Beliefs $\times$ State Attachment Anxiety interaction effect with initial forgiveness. The values in the figure represent standardized regression coefficients. The coefficient in parentheses represents the association of the Destiny Beliefs $\times$ State Attachment Anxiety interaction effect with initial forgiveness when trust is not included in the model. 


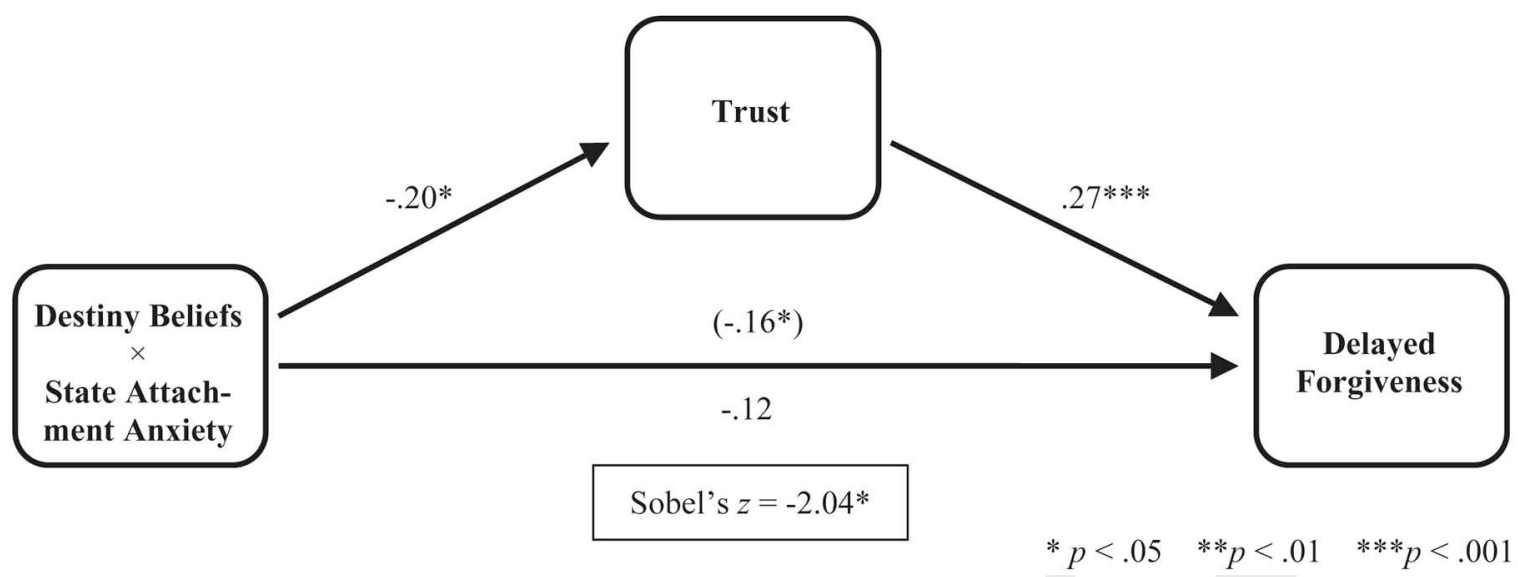

Figure 5. Study 2: Examining whether trust significantly mediates the association of the Destiny Beliefs $\times$ State Attachment Anxiety interaction effect with delayed forgiveness, controlling for earlier forgiveness. The values in the figure represent standardized regression coefficients. The coefficient in parentheses represents the association of the Destiny Beliefs $\times$ State Attachment Anxiety interaction effect with delayed forgiveness when trust is not included in the model.

the Destiny Beliefs $\times$ State Attachment Anxiety interaction effect with delayed forgiveness $(z=-2.04, p<.05) .^{12}$

We have argued that a central reason that state attachment anxiety moderates the association of destiny beliefs with forgiveness is that it focuses destiny theorists' diagnostic tendencies onto issues of trust versus distrust. These mediational results provide strong support for this conceptual analysis. Toward the goal of garnering additional support for it, we established discriminant validity by replicating the mediational analyses, this time substituting in relationship closeness (Knee, 1998) for state attachment anxiety. Given that relationship closeness is not hypothesized to highlight trust-relevant issues in the way state attachment anxiety does, we anticipated that trust would not significantly mediate the Destiny Beliefs $\times$ Relationship Closeness interaction effect on delayed forgiveness. Results supported our expectations: Although the preconditions for assessing mediation were established (Baron \& Kenny, 1986), the modified Sobel (1982) test did not approach significance-and the Destiny Beliefs $\times$ Relationship Closeness interaction effect remained significant after including trust in the model. This pattern of results contrasts strikingly with those for the mediational analyses involving state attachment anxiety (see Figures 4 and 5) and provides evidence that the processes at play in the Destiny Beliefs $\times$ State Attachment Anxiety interaction effects presented above function through different pathways from the moderated destiny beliefs findings established in previous research.

\section{Growth Beliefs-Exploratory Analyses}

As argued in the Introduction and as supported in Study 1, we did not predict that growth beliefs would interact with state attachment anxiety to predict forgiveness. For exploratory reasons, however, we replicated the central analyses reported above, this time replacing destiny beliefs with growth beliefs. We first crosssectionally regressed our measure of initial forgiveness on our measures of growth beliefs, state attachment anxiety, and their interaction term. Contrary to our expectations and to the Study 1 results, the interaction effect was significant (in the opposite direction of the destiny interaction effect), $\beta=.14, t(132)=2.11$, $p=.04$. Tests of simple slopes revealed a nonsignificant association of growth beliefs with initial forgiveness among individuals experiencing state attachment anxiety (i.e., high anxiety), $\beta=.07$, $t(132)=0.69, p=.49$, but a (nearly) significant negative association among individuals experiencing state attachment security (i.e., low anxiety), $\beta=-.20, t(132)=-1.83, p=.07$.

Before drawing firm conclusions, however, we also replicated the primary longitudinal analysis predicting delayed forgiveness reported above, substituting in growth beliefs for destiny beliefs. The Growth Beliefs $\times$ State Attachment Anxiety interaction effect was not significant, $\beta=-.08, t(109)=-0.92, p=.36$. Taken together, the results from Studies 1 and 2 provide some inconsistent support for the possibility that growth beliefs interact with state attachment anxiety to predict forgiveness, but firm conclusions await additional research.

\section{Discussion}

The results of Study 2, then, revealed strong support for both of our hypotheses. In contrast to Study 1, support for our primary hypothesis emerged with assessments of naturally occurring fluctuations in state attachment anxiety and forgiveness regarding naturally occurring offenses and when predicting both immediate and delayed forgiveness. Study 2 also allowed for the first test of our secondary hypothesis. We now turn our attention to a more detailed discussion of the pattern of findings across the two studies.

\footnotetext{
${ }^{12}$ An auxiliary set of mediational analyses revealed that the earlier measure of trust marginally mediated the association of the marginally significant Destiny Beliefs $\times$ Earlier State Attachment anxiety with delayed forgiveness (Sobel $z=1.70, p=.09$ ).
} 


\section{General Discussion}

Taken together, the findings from Studies 1 and 2 provide strong evidence for our hypotheses. Results from both studies revealed that participants experiencing state attachment anxiety became less forgiving as the strength of their destiny beliefs increased, whereas those experiencing state attachment security exhibited no association (or, if anything, a positive association) of destiny beliefs with forgiveness tendencies (see Figures 1 through 3). These effects emerged (see Study 1) with an experimental manipulation of attachment anxiety (vs. security) and remained significant (or nearly significant; see Study 2) after controlling for trait attachment anxiety, trait attachment avoidance, trait forgiveness tendencies, self-deception, impression management, time since the offense, offense severity, relationship commitment, relationship closeness, and the Destiny Beliefs $\times$ Relationship Closeness interaction effect that had been previously identified (Knee, 1998) as a predictor of relationship outcomes. The longitudinal effect also controlled for earlier forgiveness tendencies. The Destiny Beliefs $\times$ State Attachment Anxiety interaction effect, then, emerged in all relevant analyses and was extraordinarily robust.

Supporting our secondary hypothesis, results from Study 2 also revealed that the association of the Destiny Beliefs $\times$ State Attachment Anxiety interaction effect with both initial and delayed forgiveness was significantly but partially mediated through partner-specific trust (see Figures 4 and 5). These results are consistent with our assertion that strong destiny theorists who are experiencing state attachment anxiety are unforgiving in large part because they lack confidence that good outcomes will ensue if they forgive their partner's offenses.

\section{A Vicious Cycle?}

Previous research demonstrates that relative to forgiveness, lack of forgiveness is associated with poor relationship functioning (Fincham et al., 2004; Gordon \& Baucom, 2003; Rusbult et al., 2005). The present research demonstrates that strong destiny theorists tend to be unforgiving of partner offenses when they are experiencing state attachment anxiety (vs. security). Taken together, these findings suggest that such destiny theorists may be susceptible to a vicious cycle of insecurity and relationship difficulties once insecurity first seeps into their psyche. Imagine that Lisa adheres strongly to destiny beliefs. Her relationship with Bill had been going smoothly, but she believes that he recently betrayed her by having dinner with his ex-girlfriend. To the degree that she experiences state attachment anxiety after learning about the dinner, she is likely to experience distrust in Bill and ultimately to take an unforgiving stance regarding his behavior-both immediately and over time. This prolonged lack of forgiveness could reinforce her diagnostic orientation toward the relationship and her need for reassurance (not to mention the effects it is likely to have on Bill's evaluation of the relationship), ultimately resulting in (a) her perceiving rejection where none was intended (e.g., Holmes \& Rempel, 1989; Murray, Holmes, MacDonald, \& Ellsworth, 1998) and (b) her behaving in a rejection-sensitive manner that actually elicits real rejection (e.g., Downey, Freitas, Michaelis, \& Khouri, 1998) — and the vicious cycle is reinforced. Future research could test the validity of this vicious cycle hypothesis.

\section{A Social Psychological Analysis of Attachment Dynamics}

More generally, we approach adult attachment dynamics from a distinctly social psychological perspective. As discussed previously, the vast majority of research on adult attachment dynamics has studied attachment representations as stable individual difference variables. The present research conceptualized these representations from a social cognitive perspective (Baldwin et al., 1996; Davila et al., 1999; Davila \& Sargent, 2003; also see Baldwin, 1992) as state-level variables that can fluctuate as a function of experimental priming (Study 1) or naturally occurring life circumstances (Study 2). In both studies, state attachment anxiety interacted as hypothesized with destiny beliefs to predict forgiveness tendencies after controlling for trait attachment tendencies (and trait forgiveness tendencies, for that matter). As such, our conclusions are not about individuals who are characterized by insecure versus secure attachment systems (or by unforgiving vs. forgiving dispositions); rather, they are about individuals in general who, like everybody else, experience temporary fluctuations in their state attachment anxiety over time. Although we are impressed with the enormous success achieved by scholars who conceptualize attachment representations in terms of individual differences, we believe that increased attention to state-level fluctuations in attachment representations will lead to a more complete understanding of attachment dynamics, perhaps even allowing scholars to investigate certain topics that are difficult to study from an individual difference perspective. The present results provide one compelling example: State attachment anxiety moderated the association of destiny beliefs with forgiveness tendencies, but this effect was not detectable with measures of trait attachment anxiety. We believe that attachment theory can benefit from complementing continued research on individual differences with a greater emphasis on within-person variability in attachment representations. Assessing both trait and state measures in the same sample of participants (as done herein) promises to provide a particularly rich and textured picture of attachment processes (see also Cozzarelli et al., 2000; Pierce \& Lydon, 2001).

\section{Implications for Research on Implicit Theories of Relationships}

Research on implicit theories of relationships has flourished in recent years, and scholars have identified important moderators of the association between implicit theories and relationship outcomes. One limitation of this body of research, however, is that there exist no studies (to our knowledge) that identify a mediator of any of these moderational effects. Researchers have presented compelling arguments that implicit theories operate through the assignment of meaning to relationship events: "While ITRs [implicit theories of relationships] have often been found to moderate how relationship events and perceptions predict relationship outcomes, it is really the meaning that is assigned, because of the ITRs, that is key" (Knee \& Canevello, 2006, pp. 164-165). In the present article, we have presented theoretical arguments (and found evidence in Study 2 to support) that trust in one's partner (a meaning-relevant variable) partially mediates the interactive effect of destiny beliefs and state attachment anxiety on forgiveness tendencies. Trust is a distilled representation of the degree to which individuals perceive that their partner will provide them 
with good outcomes in their relationship (Holmes \& Rempel, 1989) and, as such, serves as an exemplar of the sort of meaning analysis individuals conduct in response to relationship events. We investigated trust as a mediator in the present research because the attachment system renders trust a central concern (e.g., Mikulincer, 1998); it is likely that other moderational effects involving implicit theories will be mediated through different meaningrelevant variables.

\section{Limitations and Strengths}

We highlight several limitations of the present research. First, like much research in personality and social psychology, our sample was limited to university students in the United States. It seems plausible that there could be cultural differences in adherence to destiny beliefs or that the processes identified herein would function differently in marital relationships. Future research could fruitfully explore issues such as these.

Second, the current research did not use behavioral measures of forgiveness. Although one could readily make the case that selfreports serve as an optimal measure of forgiveness processes, our conclusions would be bolstered by replications using behavioral forgiveness measures.

Third, the Study 2 measures on the biweekly online questionnaires were assessed with brief assessment instruments. In an ideal world, participants would have completed full-length measures of all constructs at all time points, but such an approach would have filling out these questionnaires 14 times over a 6-month period onerous, likely resulting in troubling attrition rates. Although most of our brief measures (e.g., forgiveness, trust) have superb face validity, we acknowledge that our need for reassurance measure may not entirely capture the construct of attachment anxiety. This concern is mitigated somewhat because (a) the Study 1 priming procedure activating standard attachment anxiety themes (e.g., the child felt vulnerable) revealed a similar Destiny Beliefs $\times$ State Attachment Anxiety interaction effect to that from Study 2, (b) there is a virtual consensus that attachment anxiety is a unidimensional construct (suggesting that any given item from the scale should represent an exemplar of the entire scale), (c) statistical investigations have provided compelling evidence that 1-item measures provide reasonable proxies for their full-length scales (e.g., Wanous \& Hudy, 2001), and (d) results from the pilot study reported in our Study 2 Method section demonstrate that the need for reassurance correlates very strongly with the other 17 items in a full-length partner-specific anxiety measure. These four reasons suggest that it is parsimonious to conclude that our 1-item need for reassurance measure does indeed capture the essence of state attachment anxiety. In addition, the most substantial drawback of using brief but valid measures is that their unreliability diminishes the likelihood of detecting effects that actually exist in the population; finding such effects in spite of this diminished reliability arguably provides especially strong support for the hypotheses. Nonetheless, it may make sense to interpret our Study 2 results as pertaining specifically to the need for reassurance component of attachment anxiety.

We also highlight several strengths of the present research. First, it merges ideas derived from research on implicit theories of relationships with ideas derived from attachment theory to identify processes that advance our understanding of both research do- mains - and of the forgiveness domain. The mediated moderational results provide a rich picture of the mechanisms at work.

Second, the methods used in one study complement those used in the other and collectively avoid most of the methodological pitfalls plaguing much forgiveness research. Both studies, for example, avoided the use of retrospective reports of forgiveness regarding offenses from the distant past, reports that are especially subject to memory bias. In addition, assessing participants' implicit theories in both studies before they experienced the offenses rules out the reverse-causality concern that the offenses we studied (or the forgiveness tendencies in response to them) influenced our measure of implicit theories. In Study 1, we maximized experimental control by manipulating state attachment anxiety (vs. security) and by standardizing the severity of the partner offenses. This study allows us to draw causal conclusions about how state attachment anxiety moderates the association of destiny beliefs with forgiveness tendencies. In Study 2, we examined real offenses in ongoing romantic relationships, allowing us to avoid the use of hypothetical offense scenarios (which might well fail to elicit the affective responses of real offenses). We also performed exceptionally conservative confound analyses in Study 2 and found that the Destiny Beliefs $\times$ State Attachment Anxiety interaction effect is remarkably robust.

Third, our longitudinal methods allowed us to assess not only initial forgiveness in response to the offense but also delayed forgiveness 2 weeks later; all analyses predicting delayed forgiveness controlled for earlier forgiveness. These analyses were especially rigorous (even compared to other residualized-lagged analyses) because we supplied participants at the follow-up assessments with their own verbatim descriptions of the offense as they themselves reported it 2 weeks earlier, a methodological feature that minimizes the likelihood of simply forgetting why the incident was upsetting in the first place.

\section{Conclusion}

Experiencing partner offenses is almost inevitable in romantic relationships, and gut-level reactions to such offenses frequently tend toward retaliation. Prior research suggests, however, that enacting forgiving responses predicts positive relational and personal outcomes. The present report revealed that individuals experiencing state attachment anxiety become less forgiving as the strength of their destiny beliefs increases, whereas those experiencing state attachment security exhibit no reliable association of destiny beliefs with forgiveness tendencies. It also revealed that the association of this Destiny Beliefs $\times$ State Attachment Anxiety interaction effect with reduced forgiveness is partially mediated by the experience of trust in the partner. This research marries the burgeoning literatures on forgiveness and implicit theories of relationships to the longstanding and comprehensive literature on attachment dynamics, and hints at the likely fruits of this marriage.

\section{References}

Aiken, L. S., \& West, S. G. (1991). Multiple regression: Testing and interpreting interactions. Thousand Oaks, CA: Sage.

Ainsworth, M. D. S., Blehar, M., Waters, E., \& Wall, S. (1978). Patterns of attachment. Hillsdale, NJ: Erlbaum.

Baldwin, M. W. (1992). Relational schemas and the processing of social information. Psychological Bulletin, 112, 461-484. 
Baldwin, M. W., \& Fehr, B. (1995). On the instability of attachment style ratings. Personal Relationships, 2, 247-261.

Baldwin, M. W., Fehr, B., Keedian, E., Seidel, M., \& Thomson, D. W. (1993). An exploration of the relational schemata underlying attachment styles: Self report and lexical decision approaches. Personality and Social Psychology Bulletin, 19, 746-754.

Baldwin, M. W., Keelan, J. P. R., Fehr, B., Enns, V., \& Koh-Rangarajoo, E. (1996). Social-cognitive conceptualization of attachment working models: Availability and accessibility effects. Journal of Personality and Social Psychology, 71, 94-109.

Bargh, J. A., \& Chartrand, T. L. (2000). The mind in the middle: A practical guide to priming and automaticity research. In H. T. Reis \& C. M. Judd (Eds.), Handbook of research methods in social and personality psychology (pp. 253-285). New York: Cambridge University Press.

Baron, R. M., \& Kenny, D. A. (1986). The moderator-mediator variable distinction in social psychological research: Conceptual, strategic, and statistical considerations. Journal of Personality and Social Psychology, 51, 1173-1182.

Bartholomew, K., \& Horowitz, L. M. (1991). Attachment styles among young adults: A test of a four-category model. Journal of Personality and Social Psychology, 61, 226-244.

Bolger, N., Davis, A., \& Rafaeli, E. (2003). Diary methods. Capturing life as it is lived. Annual Review of Psychology, 54, 579-616.

Bowlby, J. (1973). Attachment and loss: Vol. 2. Separation. New York, NY: Basic Books.

Bowlby, J. (1982). Attachment and loss: Vol. 1. Attachment (2nd ed.). New York: Basic Books.

Brennan, K. A., Clark, C. L., \& Shaver, P. R. (1998). Self-report measurement of adult attachment: An integrative overview. In J. A. Simpson \& W. S. Rholes (Ed.), Attachment theory and close relationships (pp. 46-76). New York: Guilford Press.

Brown, R. P. (2003). Measuring individual differences in the tendency to forgive: Construct validity and links with depression. Personality and Social Psychology Bulletin, 29, 759-771.

Brown, R. P., \& Phillips, A. (2005). Letting bygones be bygones: Further evidence for the validity of the Tendency to Forgive Scale. Personality and Individual Differences, 38, 627-638.

Campbell, L., Simpson, J. A., Boldry, J., \& Kashy, D. A. (2005). Perceptions of conflict and support in romantic relationships: The role of attachment anxiety. Journal of Personality and Social Psychology, 88, $510-531$.

Collins, N. L. (1996). Working models of attachment: Implications for explanation, emotion, and behavior. Journal of Personality and Social Psychology, 71, 810-832.

Collins, N. L., \& Allard, L. M. (2001). Cognitive representations of attachment: The context and function of working models. In G. J. O. Fletcher \& M. S. Clark (Eds.), Blackwell handbook of social psychology: Interpersonal processes (pp. 60-85). Malden, MA: Blackwell.

Collins, N. L., \& Read, S. J. (1990). Adult attachment, working models, and relationship quality in dating couples. Journal of Personality and Social Psychology, 58, 644-663.

Cook, W. L. (2000). Understanding attachment security in family context. Journal of Personality and Social Psychology, 78, 285-294.

Cozzarelli, C., Hoekstra, S. J., \& Bylsma, W. H. (2000). General versus specific mental models of attachment: Are they associated with different outcomes? Personality and Social Psychology Bulletin, 26, 605-618.

Davila, J., Karney, B. R., \& Bradbury, T. N. (1999). Attachment change processes in the early years of marriage. Journal of Personality and Social Psychology, 76, 783-802.

Davila, J., \& Sargent, E. (2003). The meaning of life (events) predicts changes in attachment security. Personality and Social Psychology Bulletin, 29, 1383-1395.

Downey, G., Freitas, A. L., Michaelis, B., \& Khouri, H. (1998). The self-fulfilling prophecy in close relationships: Rejection sensitivity and rejection by romantic partners. Journal of Personality and Social Psychology, 75, 545-560.

Dweck, C. S. (2006). Mindset: The new psychology of success. New York: Random House.

Fincham, F. D., Beach, S. R. H., \& Davila, J. (2004). Forgiveness and conflict resolution in marriage. Journal of Family Psychology, 18, 7281.

Finkel, E. J., Rusbult, C. E., Kumashiro, M., \& Hannon, P. A. (2002). Dealing with betrayal in close relationships: Does commitment promote forgiveness? Journal of Personality and Social Psychology, 82, 956974.

Fraley, R. C., \& Shaver, P. R. (1998). Airport separations: A naturalistic study of adult attachment dynamics in separating couples. Journal of Personality and Social Psychology, 75, 1198-1212.

Fraley, R. C., \& Shaver, P. R. (2000). Adult romantic attachment: Theoretical developments, emerging controversies, and unanswered questions. Review of General Psychology, 4, 132-154.

Franiuk, R., Cohen, D., \& Pomerantz, E. M. (2002). Implicit theories of relationships: Implications for relationship satisfaction and longevity. Personal Relationships, 9, 345-367.

Franiuk, R., Pomerantz, E. M., \& Cohen, D. (2004). The causal role of theories of relationships: Consequences for satisfaction and cognitive strategies. Personality and Social Psychology Bulletin, 30, 194-1507.

Gordon, K. C., \& Baucom, D. H. (2003). Forgiveness and marriage: Preliminary support for a synthesized model of recovery from a marital betrayal. American Journal of Family Therapy, 31, 179-199.

Gottman, J. M. (1998). Psychology and the study of the marital processes. Annual Review of Psychology, 49, 169-197.

Green, J. D., \& Campbell, W. K. (2000). Attachment and exploration in adults: Chronic and contextual accessibility. Personality and Social Psychology Bulletin, 26, 452-461.

Hazan, C., \& Shaver, P. (1987). Romantic love conceptualized as an attachment process. Journal of Personality and Social Psychology, 52, 511-524.

Holmes, J. G., \& Murray, S. L. (1996). Conflict in close relationships. In E. T. Higgins \& A. Kruglanski (Eds.), Social psychology: Handbook of basic principles (pp. 622-654). New York: Guilford Press.

Holmes, J. G., \& Rempel, J. K. (1989). Trust in close relationships. In C. Hendrick (Ed.), Review of personality and social psychology (Vol. 10, pp. 187-220). Newbury Park, CA: Sage.

Kenny, D. A., Kashy, D. A., \& Bolger, N. (1998). Data analysis in social psychology. In D. T. Gilbert, S. T. Fiske, \& Lindzey, G. (Eds.). Handbook of social psychology (4th ed., pp. 233-265). New York: Oxford University Press.

Kenny, D. A., Mannetti, L., Pierro, A., Livi, S., \& Kashy, D. A. (2002). The statistical analysis of data from small groups. Journal of Personality and Social Psychology, 83, 126-137.

Knee, C. R. (1998). Implicit theories of relationships: Assessment and prediction of romantic relationship initiation, coping, and longevity. Journal of Personality and Social Psychology, 74, 360-370.

Knee, C. R., \& Canevello, A. (2006). Implicit theories of relationships and coping in romantic relationships. In K. D. Vohs \& E. J. Finkel (Eds.), Self and relationships: Connecting intrapersonal and interpersonal processes (pp. 160-176). New York: Guilford Press.

Knee, C. R., Nanayakkara, A., Vietor, N. A., Neighbors, C., \& Patrick, H. (2001). Implicit theories of relationships: Who cares if romantic partners are less than ideal? Personality and Social Psychology Bulletin, 27, $808-819$.

Knee, C. R., Patrick, H., \& Lonsbary, C. (2003). Implicit theories of relationships: Orientation toward evaluation and cultivation. Personality and Social Psychology Review, 7, 41-55.

Knee, C. R., Patrick, H., Vietor, N. A., \& Neighbors, C. (2004). Implicit 
theories of relationships: Moderators of the link between conflict and commitment. Personality and Social Psychology Bulletin, 30, 617-628.

La Guardia, J. G., Ryan, R. M., Couchman, C. E., \& Deci, E. L. (2000). Within-person variation in security of attachment: A self-determination theory perspective on attachment, need fulfillment, and well-being. Journal of Personality and Social Psychology, 79, 367-384.

Lawler, K. A., Younger, J. W., Piferi, R. L., Billington, E., Jobe, R., Edmondson, K., \& Jones, W. H. (2003). A change of heart: Cardiovascular correlates of forgiveness in response to interpersonal conflict. Journal of Behavioral Medicine, 26, 373-393.

McCullough, M. E., \& Hoyt, W. T. (2002). Transgression-related motivational dispositions: Personality substrates of forgiveness and their links to the Big Five. Personality and Social Psychology Bulletin, 28, 15561573.

Mikulincer, M. (1998). Attachment working models and the sense of trust: An exploration of interaction goals and affect regulation. Journal of Personality and Social Psychology, 74, 1209-1224.

Mikulincer, M., \& Shaver, P. R. (2003). The attachment behavioral system in adulthood: Activation, psychodynamics, and interpersonal processes. In M. P. Zanna (Ed.), Advances in experimental social psychology (Vol. 35, pp. 53-152). New York: Academic Press.

Mikulincer, M., Shaver, P., Gillath, O., \& Nitzberg, R. A. (2005). Attachment, caregiving, and altruism: Boosting attachment security increases compassion and helping. Journal of Personality and Social Psychology, 89, 817-839.

Molden, D. C., \& Dweck, C. S. (2006). Finding "meaning" in psychology: A lay theories approach to self-regulation, social perception, and social development. American Psychologist, 61, 192-203.

Murray, S. L., Bellavia, G. M., Rose, P., \& Griffin, D. W. (2003). Once hurt, twice hurtful: How perceived regard regulates daily marital interactions. Journal of Personality and Social Psychology, 84, 126-147.

Murray, S. L., \& Holmes, J. G. (2000). Seeing the self through a partner's eyes: Why self-doubts turn into relationship insecurities. In A. Tesser, R. B. Felson, \& J. M. Suls (Eds.), Psychological perspectives on self and identity (pp. 173-198). Washington, DC: APA Press.

Murray, S. L., Holmes, J. G., MacDonald, G., \& Ellsworth, P. C. (1998). Through the looking glass darkly?: When self-doubts turn into relationship insecurities. Journal of Personality and Social Psychology, 75, $1459-1480$.

Murray, S. L., Rose, P., Holmes, J. G., Derrick, J., Podchaski, E. J., Bellavia, G., \& Griffin, D. W. (2005). Putting the partner within reach: A dyadic perspective on felt security in close relationships. Journal of Personality and Social Psychology, 88, 327-347.

Nezlek, J. B. (2001). Multilevel random coefficient analyses of event- and interval-contingent data in social and personality psychology research. Personality and Social Psychology Bulletin, 27, 771-785.

Paulhus, D. L. (1984). Two-component models of socially desirable responding. Journal of Personality and Social Psychology, 46, 598-609.

Pierce, T., \& Lydon, J. E. (2001). Global and specific relational models in the experience of social interactions. Journal of Personality and Social Psychology, 80, 613-631.

Raudenbush, S. W., \& Bryk, A. S. (2002). Hierarchical linear models: Applications and data analysis methods. Thousand Oaks, CA: Sage.

Rusbult, C. E., Davis, J. L., Finkel, E. J., Hannon, P. A., \& Olsen, N.
(2006). Forgiveness of betrayal in close relationships: A dual process model of the transformation from self-interested impulses to relationship-oriented actions. Manuscript under review.

Rusbult, C. E., Hannon, P. A., Stocker, S. L., \& Finkel, E. J. (2005). Forgiveness and relational repair. In E. L. Worthington Jr. (Ed.), Handbook of forgiveness (pp. 185-205). New York: Brunner-Routledge.

Ruvolo, A. P., \& Rotondo, J. L. (1998). Diamonds in the rough: Implicit personality theories and views of partner and self. Personality and Social Psychology Bulletin, 24, 750-758.

Shaver, P. R., Collins, N., \& Clark, C. L. (1996). Attachment styles and internal working models of self and relationship partners. In G. J. O. Fletcher \& J. Fitness (Eds.), Knowledge structures in close relationships: A social psychological approach (pp. 25-61). Hillsdale, NJ: Erlbaum.

Simpson, J. S., Rholes, W. S., \& Phillips, D. (1996). Conflict in close relationships: An attachment perspective. Journal of Personality and Social Psychology, 71, 899-914.

Sobel, M. E. (1982). Asymptotic confidence intervals for indirect effects in structural models. In S. Leinhardt (Ed.), Sociological methodology (pp. 290-312). San Francisco: Jossey-Bass.

Sroufe, L. A., \& Waters, E. (1977). Attachment as an organizational construct. Child Development, 48, 1184-1199.

Srull, T. K., \& Wyer, R. S., Jr. (1979). Category accessibility and social perception: Some implications for the study of person memory and interpersonal judgments. Journal of Personality and Social Psychology, 37, $1660-1672$.

Sullivan, H. S. (1953). The interpersonal theory of psychiatry. New York: Norton.

Toussaint, L. L., Williams, D. R., Musick, M. A., \& Everson, S. A. (2001). Forgiveness and health: Age differences in a U.S. probability sample. Journal of Adult Development, 8, 249-257.

Treboux, D., Crowell, J. A., \& Waters, E. (2004). When "new" meets "old": Configurations of adult attachment representations and their implications for marital functioning. Developmental Psychology, 40, 295314.

Wanous, J. P., \& Hudy, M. J. (2001). Single-item reliability: A replication and extension. Organizational Research Methods, 4, 361-375.

Wanous, J. P., Reichers, A. E., \& Hudy, M. J. (1997). Overall job satisfaction: How good are single-item measures? Journal of Applied Psychology, 82, 247-252.

Whisman, M. A., \& Allan, L. E. (1996). Attachment and social cognition theories of romantic relationships: Convergent or complementary perspectives? Journal of Social and Personal Relationships, 13, 263-278.

Witvliet, C. V. O., Ludwig, T. E., \& Vander Laan, K. L. (2001). Granting forgiveness or harboring grudges: Implications for emotion, physiology, and health. Psychological Science, 121, 117-123.

Worthington, E. L., Jr., \& Scherer, M. (2004). Forgiveness as an emotionfocused coping strategy that can reduce health risks and promote health resilience: Theory, review, and hypotheses. Psychology and Health, 19, $385-405$.

Received October 9, 2005

Revision received September 29, 2006

Accepted October 1, 2006 